Paper:

\title{
Implementation of Building Monitoring Network in Peru Under SATREPS Project
}

\author{
Miguel Diaz*, Patricia Gibu*, Lucio Estacio**, and Ricardo Proaño* \\ ${ }^{*}$ Faculty of Civil Engineering, National University of Engineering \\ Av. Tupac Amaru 1150, Lima 25, Peru \\ E-mail:mdiazf@uni.edu.pe \\ ** Japan Peru Center for Earthquake Engineering and Disaster Mitigation \\ Av. Tupac Amaru 1150, Lima 25, Peru \\ [Received August 1, 2014; accepted September 18, 2014]
}

\begin{abstract}
Under the Peru-Japan SATREPS Project, a building monitoring system has been implemented in Lima city, supported by JST and JICA. This network monitors three buildings (HERM, PC-UNI and FIC-UNI); each building has five sensors, which consist in a GMR accelerometers. These buildings have different characteristics, such as age, ground mechanic properties, structural systems, and structural status. Since the implementation of this network, some quakes have been recorded. This paper describes the implementation of the monitoring network, and presents the response of the target buildings and their dynamics characteristics during these quakes.
\end{abstract}

Keywords: building monitoring, dynamic characteristics, structural health monitoring

\section{Introduction}

After major earthquake, buildings have to be investigated one by one, by engineers or researchers in order to determine if the target building may or may not survive subsequent quakes, such as aftershocks. The aim of the post-earthquake quick inspection is to avoid secondary disasters, by inspecting buildings hit by major earthquakes and evaluating the risks of the building collapse. Post-evaluation placards are posted on damaged buildings to inform not only inhabitants but also passersby of the risks. Placard posting system relieves the anxiety of inhabitants, because building engineers actually inspected each building. Thus, the quick inspection system presents a dilemma since buildings should be investigated by visual observation of engineers. So then, judgment varies according to engineers' or researches' experience.

Structural Health Monitoring (SHM) systems is a relatively new term for civil engineering applications; SHM can be considered as a system comprising sensing instruments and other ancillary systems, which can provide on demand information pertaining to the conditions of the structure that enables the assessment of the safety and integrity of infrastructures systems (Shoureshi, 2003).

In that sense, it is desirable a method for the quick in- spection after a major earthquake which can take an advantage of the availability of the building monitoring network. Thus, a uniform judgment would be applied into the evaluation of building conditions after a significant earthquake, and anticipate if buildings may or may not resist the subsequent aftershocks [3].

Under the Peru-Japan SATREPS Project a building monitoring network has been implemented in Lima city since 2011, which is supported by JST and JICA. This network considers a set of five sensors installed on different levels of three buildings, namely Block A of the Edgardo Rebagliati Martins Hospital (HERM), The Main Building of the National University of Engineering (PCUNI) and Block G of the Faculty of Civil Engineering of the National university of Engineering (FIC-UNI). These buildings are typical structures in Lima City built on two types of soils.

Since the installation of sensors, some quakes have been recorded. Thereby, the target buildings can be investigated by evaluating the dynamics characteristics using the recorded data. Moreover, the building status can immediately be determined after some quake by damage detection from the measurement of vibrations [6-8].

This study presents characteristics of the building monitoring network, the target buildings and their response during stronger quakes. Besides, the dynamics characteristics obtained by the recorded data from stronger quakes are compared with the theoretical results obtained from former studies conducted to target buildings.

\section{Implementation of the Building Monitoring Network in Lima City}

\subsection{Target Buildings}

The target buildings were supposed to be representative buildings according to the most used structural systems in Peru. These buildings are more than 50 years old and were modified during their life due to different reasons; such as occupancy, rehabilitation, and retrofitting. The target buildings are as follows:

Block A of Edgardo Rebagliati Martins Hospital (HERM) is a framed RC building of fourteen stories, built 


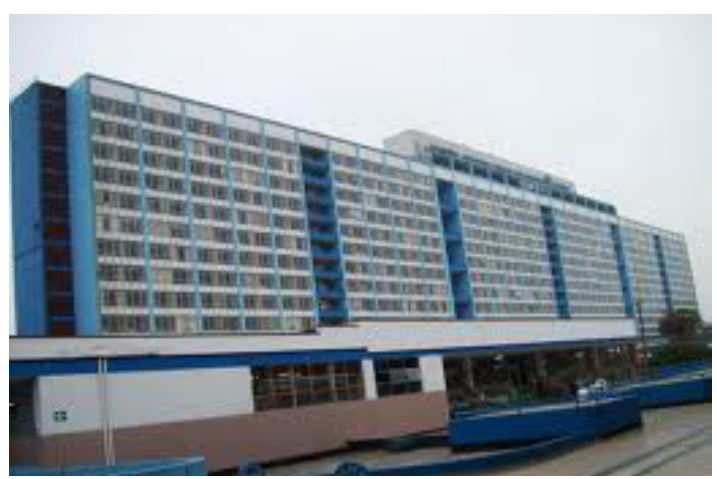

Fig. 1. Edgardo Rebagliati Martins Hospital.

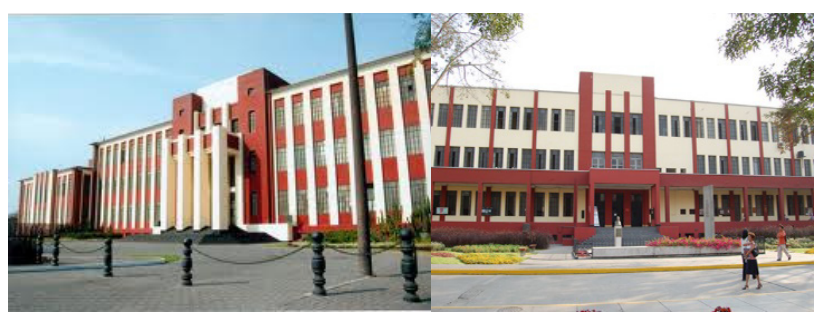

Fig. 2. Main building of the National University of Engineering.

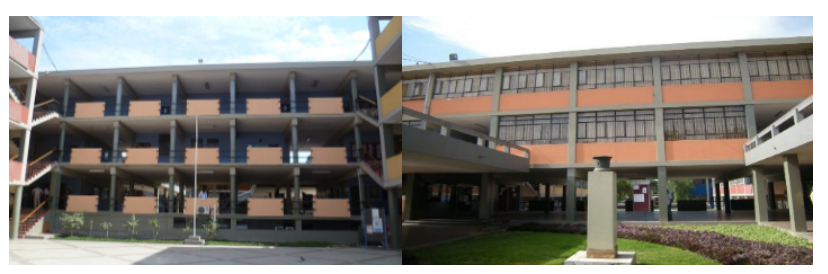

Fig. 3. Block $\mathrm{G}$ of the Faculty of Civil Engineering.

\section{in 1958 (Fig. 1).}

The Main Building of the National University of Engineering (PC-UNI) is a framed RC building of one basement and three stories used as administrative offices, built in 1945 (Fig. 2).

Block $\mathrm{G}$ of the Faculty of Civil Engineering of the National university of Engineering (FIC-UNI) is a classroom building which consists RC frames with infill walls, built in 1955 (Fig. 3).

According to the occupancy prescribed in the Peruvian Earthquake Resistant Standard (NTE-E.030), HERM building is classified as essential, while PC-UNI and FICUNI are classified as important.

\subsection{Sensors Network Setting}

Accelerometers are connected through internal network with IP addresses to access to Internet. A scheme of the building monitoring network is shown in Fig. 4 [5].

This type of accelerometer is based on giant magneto resistance (GMR) effect. The Model number of accelerometers is ITK-002, which is manufactured by ALab Co. Specifications of GMR accelerometers are summarized in Table 1.

After preliminary testing and setting in a local network (Fig. 5), a set of five sensors has been placed in two build-

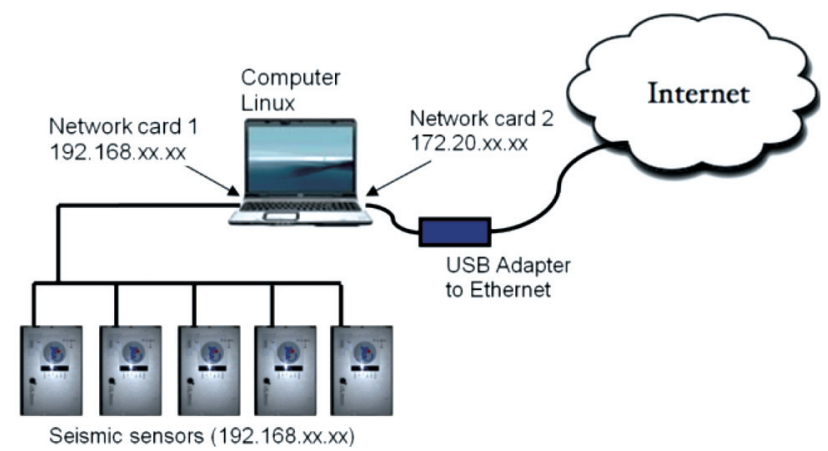

Fig. 4. Building monitoring network.

Table 1. Specifications of the GMR accelerometer.

\begin{tabular}{lc}
\hline Measuring acc. axis & $X, Y, Z(3$ axes $)$ \\
Rated capacity & $\pm 24.50 \mathrm{~m} / \mathrm{s}^{2}( \pm 2.5 \mathrm{~g})$ \\
Noise & Less than $0.1 \mathrm{~g}$ \\
Rated voltage & $\mathrm{DC} 6 \mathrm{~V} \pm 10 \%$ \\
Mounting allowable & Within $\pm 3^{\circ}$ \\
acceptance angle & NTP-dependent \\
Time accuracy & 24 bits, 100SPS \\
Sampling & Aluminum die-casting \\
Material base & Aluminum plate \\
Cover & Approx. 800 g \\
Weight &
\end{tabular}

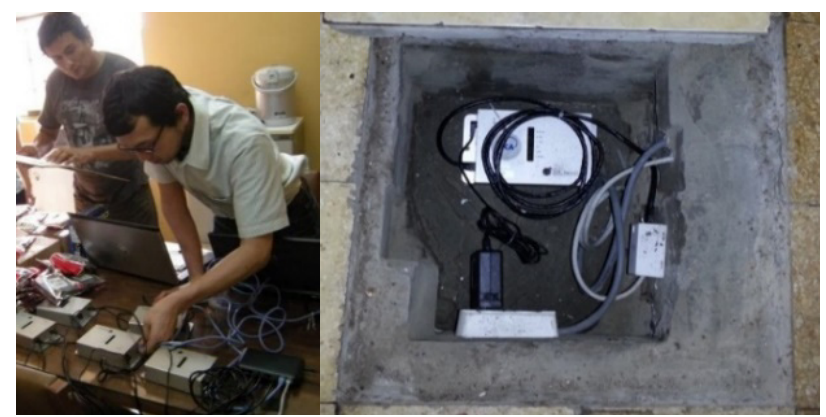

Fig. 5. Network testing and placement of sensor.

ings at the National University of Engineering (UNI) campus and one building in a hospital.

Figure 6 shows the location of accelerometers in the HERM building; they are placed at bottom part of $1^{\text {st }}$ and $11^{\text {th }}$ floor, and roof.

In the PC-UNI and the FIC-UNI buildings, accelerometers are placed at basement, bottom part of all floors and roof; which are vertically aligned, as shown in Fig. 7 and Fig. 8, respectively.

NS direction of accelerometers is parallel to the transversal direction, while EW direction is parallel to longitudinal direction, as shown in Figs. 6-8. Location of sensors in the target buildings is listed in Table 2 .

Itk-00 sensor of the HERM building is located on the basement floor; while, itk-00 sensor of PC-UNI and FICUNI buildings is located at the ground, 20 centimeters under the basement floor. 

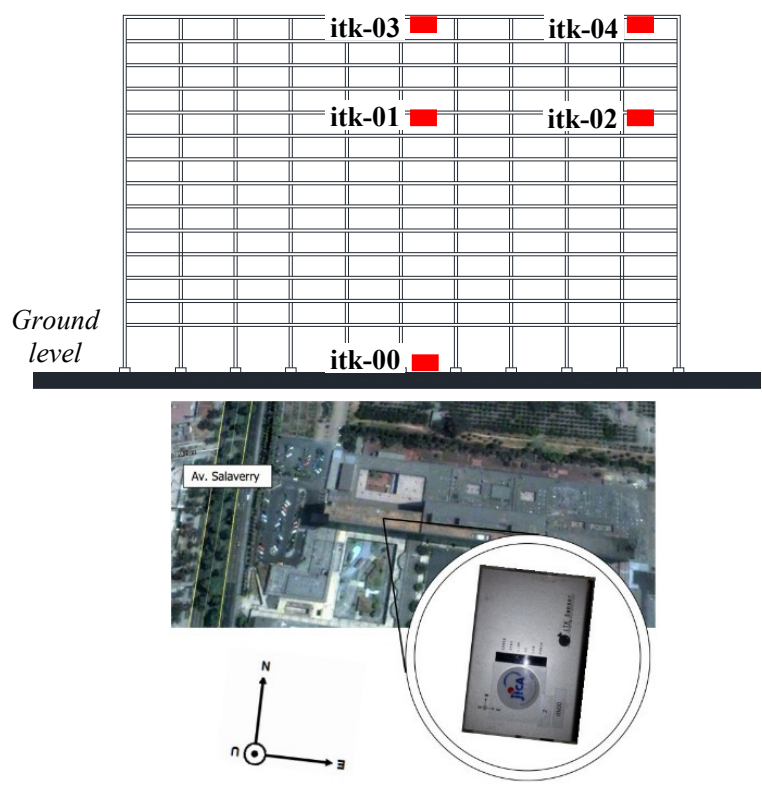

Fig. 6. Location of accelerometers in HERM.
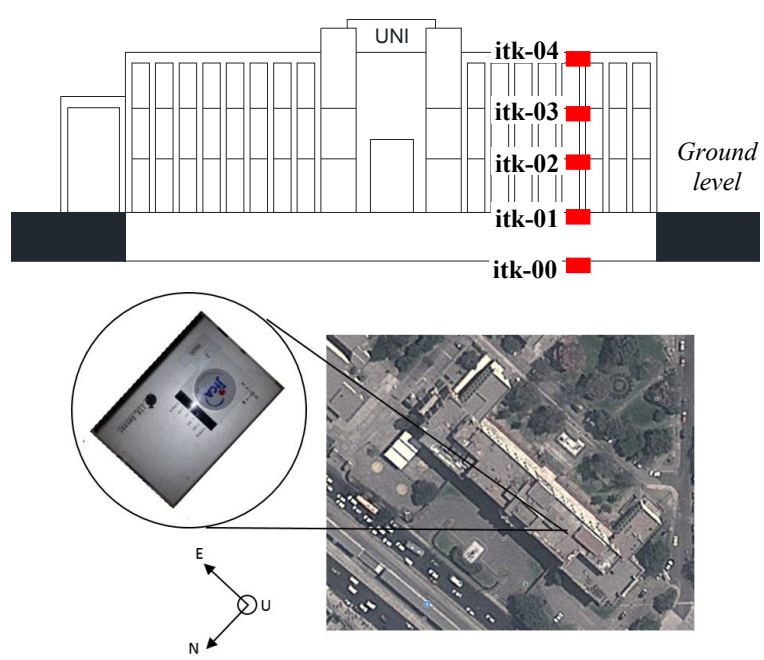

Fig. 7. Location of accelerometers in PC-UNI.

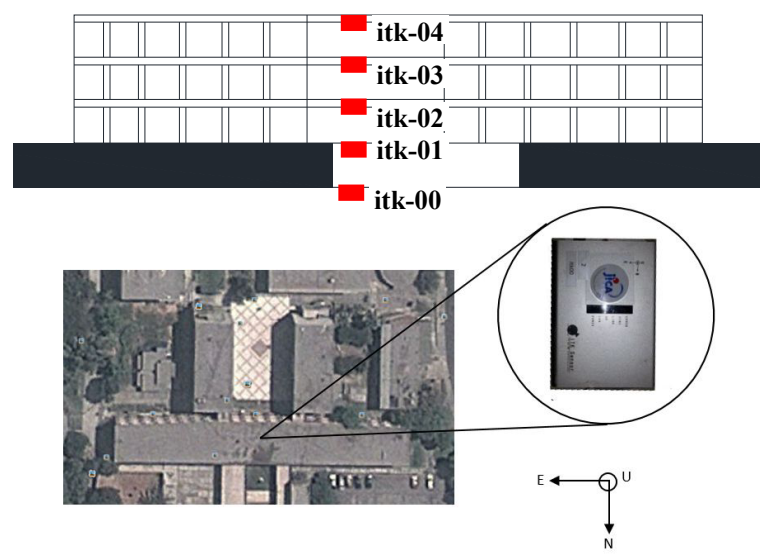

Fig. 8. Location of accelerometers in FIC-UNI.
Table 2. Location of sensors.

\begin{tabular}{cccc}
\hline $\begin{array}{c}\text { ID. } \\
\text { sensor }\end{array}$ & HERM & PC-UNI & FIC-UNI \\
\hline itk-00 & BF & BF & BF \\
itk-01 & $11 \mathrm{~F}$ & $1 \mathrm{~F}$ & $1 \mathrm{~F}$ \\
itk-02 & $11 \mathrm{~F}$ & $2 \mathrm{~F}$ & $2 \mathrm{~F}$ \\
itk-03 & RF & $3 \mathrm{~F}$ & $3 \mathrm{~F}$ \\
itk-04 & RF & RF & RF \\
\hline
\end{tabular}

\section{Former Studies on the Target Buildings}

The evaluation of existing structures is normally conducted by means of numerical simulations under certain quakes, using ground mechanics properties, mechanical properties of materials from laboratory tests.

Consequently, the evaluation of target buildings was performed by this manner, and results of PC-UNI and FIC-UNI buildings present good agreement with the microtremor measurements. These results are summarized in the following items.

\subsection{HERM}

The HERM building is a 14-stories RC structure, $15.9 \mathrm{~m} \times 73.0 \mathrm{~m}$ of length, and its height is $45.6 \mathrm{~m}$ from the ground level, founded on rock soil. It was struck by two major earthquakes (1966 and 1974), but the main structure had no damages. "Block A" was selected to be investigated which is shown in Fig. 9.

This building was subjected to two former studies: an evaluation of structural vulnerability in 1997, and a nonlinear analysis conducted in 2012, theoretical predominant periods in longitudinal and transversal directions are 1.74 seconds and 1.93 seconds, respectively [4]. According to [4], some damages are expected during moderate earthquake in beams; endangering immediately its occupancy and interrupting the normal operation of the hospital.

\subsection{PC-UNI}

The PC-UNI building is an irregular structure; the main body (central) has $117 \mathrm{~m} \times 23 \mathrm{~m}$ of length.

Some previous calculation (Fig. 10) and measurements have been conducted. Microtremor measurements have been conducted in 3 points (soil: center zone and at 3F: NO and SE wing of building); predominant periods are 0.23 seconds and 0.28 seconds in longitudinal and transversal direction, respectively [11]. The predominant period of soil is 0.41 seconds (intermediate soil).

\subsection{FIC-UNI}

The FIC-UNI building is a RC frame structure with some infill walls; it has one basement and three stories (10 m high). Half of the typical floor continues to the basement floor. First floor is the main entrance hall, and upper levels are for classroom and corridors. This structure presents a horizontal regular configuration $(28 \mathrm{~m} \times$ 


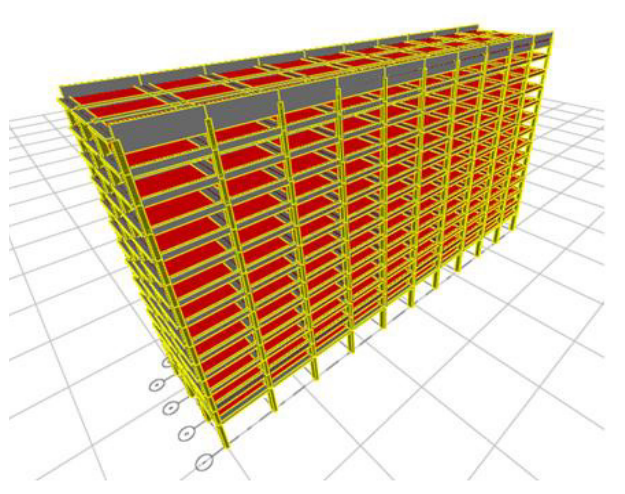

Fig. 9. 3D model of HERM building.

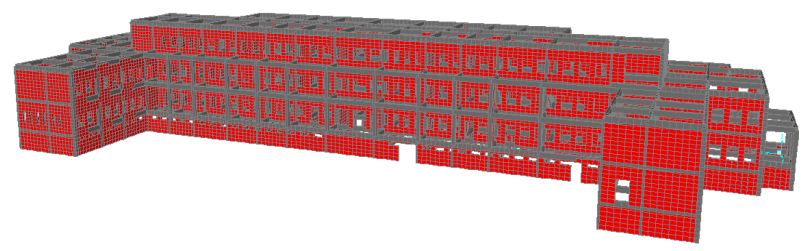

Fig. 10. 3D model of PC-UNI building.

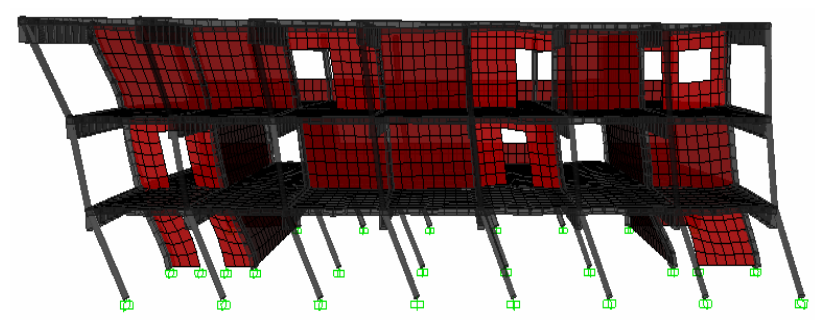

Fig. 11. 3D model of FIC-UNI building.

$12 \mathrm{~m}$, approximately); and it includes some infill masonry walls (thickness of $0.25 \mathrm{~m}$ ) which are not aligned in upper levels; thus, it presents some vertical discontinuities (soft floor).

Previous studies and evaluation of its structural vulnerability shows some values of its natural period from microtremor measurement (2007). Predominant periods in the longitudinal and transversal directions are $0.195 \mathrm{sec}-$ onds and 0.162 seconds, respectively.

The soft floor of this structure is verify with the preliminary analysis. From theoretical elastic analysis (Fig. 11), it was obtained periods of 0.31 seconds for the first mode [1] and [9].

\section{Response of the Target Buildings During Re- cent Events}

Microtremor is a low amplitude ambient vibration with some noise, and dynamics properties vary with amplitude of excitation $[2,10]$; thus, it is desirable to investigate the dynamics characteristics according to each input motion.

Table 3 shows stronger events recorded by the building monitoring network since 2012. In this table, depth,
Table 3. List of stronger recorded events.

\begin{tabular}{crrrrr}
\hline \multirow{2}{*}{ Date } & Depth & Magnitude & \multicolumn{3}{c}{ Distance $(\mathrm{km})$} \\
\cline { 4 - 6 } & $(\mathrm{km})$ & $(\mathrm{ML})$ & HERM & PC-UNI & FIC-UNI \\
\hline $2012 / 11 / 03$ & 110.0 & 4.7 & 111 & 112 & 112 \\
$2012 / 12 / 28$ & 96.0 & 4.3 & 81 & 76 & 75 \\
$2013 / 10 / 18$ & 11.0 & 4.2 & 58 & 64 & 64 \\
$2013 / 11 / 25$ & 59.0 & 5.8 & 98 & 103 & 104 \\
$2014 / 02 / 20$ & 38.0 & 4.1 & 83 & 89 & 90 \\
$2014 / 02 / 22$ & 40.0 & 4.0 & 27 & 22 & 22 \\
$2014 / 04 / 26$ & 35.0 & 4.0 & 84 & 87 & 88 \\
$2014 / 06 / 03$ & 38.0 & 5.4 & 67 & 72 & 72 \\
\hline
\end{tabular}

magnitude, and distance from the epicenter to the target buildings are shown.

Dynamics properties are obtained from the recorded data of quakes listed in Table 3. The maximum acceleration at the basement of target buildings are listed in Table 3 , in NS and EW directions. The strongest vibration was recorded on 2014/06/03, as shown in Table 3. According to the recorded data, the maximum accelerations at the basement are $14.90 \mathrm{gal}, 25.89 \mathrm{gal}$, and $26.13 \mathrm{gal}$ for the HERM, the PC-UNI and the FIC-UNI, respectively. Values of the maximum acceleration at basement of the PC-UNI and the FIC-UNI buildings are similar; because both buildings are near and their ground mechanical properties (intermediate soil) are also similar. The maximum acceleration of the HERM building is less than that of the PC-UNI and the FIC-UNI buildings, because its ground mechanical properties are different (rock soil).

\subsection{HERM}

From the recorded data, the maximum acceleration is $14.90 \mathrm{gal}$ and $12.19 \mathrm{gal}$ in NS and EW directions, respectively. This record is shown in the Fig. 12.

The maximum amplification from the acceleration at the basement to that at the roof is 3.7 and 1.7 for NS and EW directions, respectively, for the HERM building (fourteen stories).

The average predominant period using the recorded data of events listed in Table 3 is 0.98 seconds for NS and EW directions of the HERM building. This value does not present significant variation, because quakes are slight, as shown in Table 4.

The damping ratio is determined by means of the halfpower bandwidth method. The damping factor varies from 1-5\% using the events shown in Table 3.

The Fourier spectra of signals of the HERM building for the strongest event in NS and EW directions are presented in Fig. 13.

The response spectra using signals from the basement of the HERM building for the strongest event occurred in Lima since the installation of the building monitoring network are shown in Fig. 14. It can be noted that the maximum response is small, since input motions contain small amplitudes. 


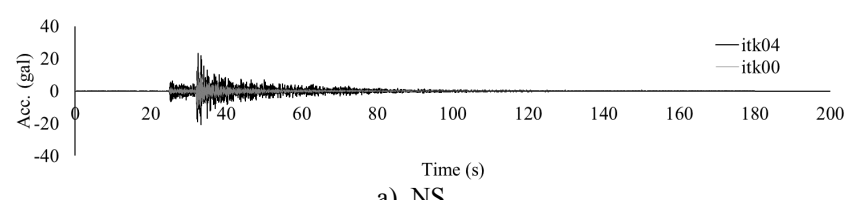

a) NS

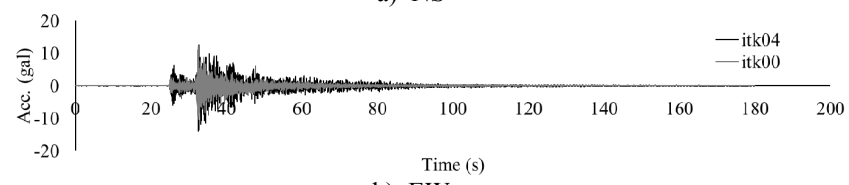

b) $\mathrm{EW}$

Fig. 12. 3D model of FIC-UNI building

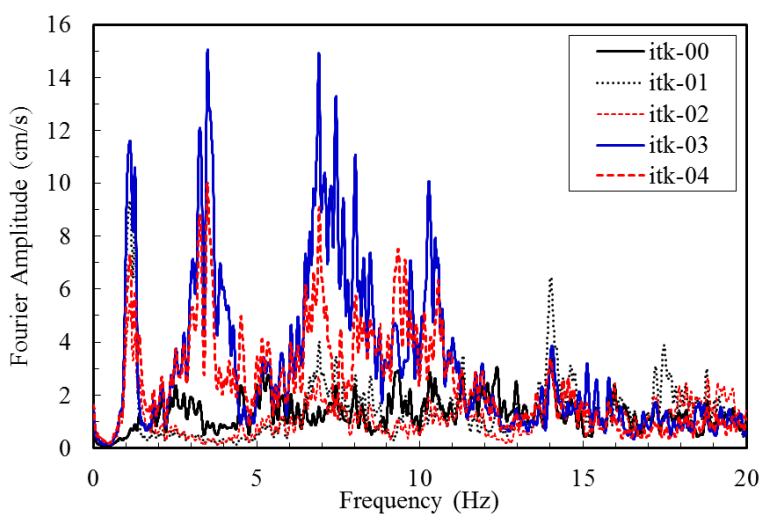

a) NS

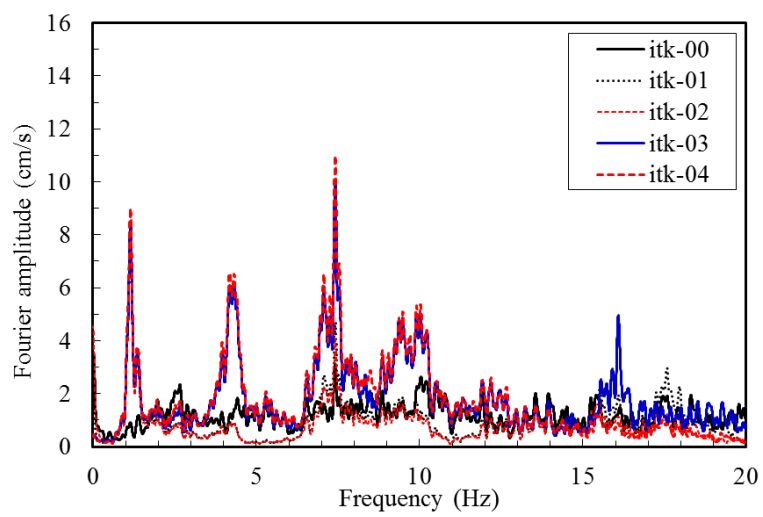

b) $\mathrm{EW}$

Fig. 13. Fourier spectra. HERM building - June 3, 2014.

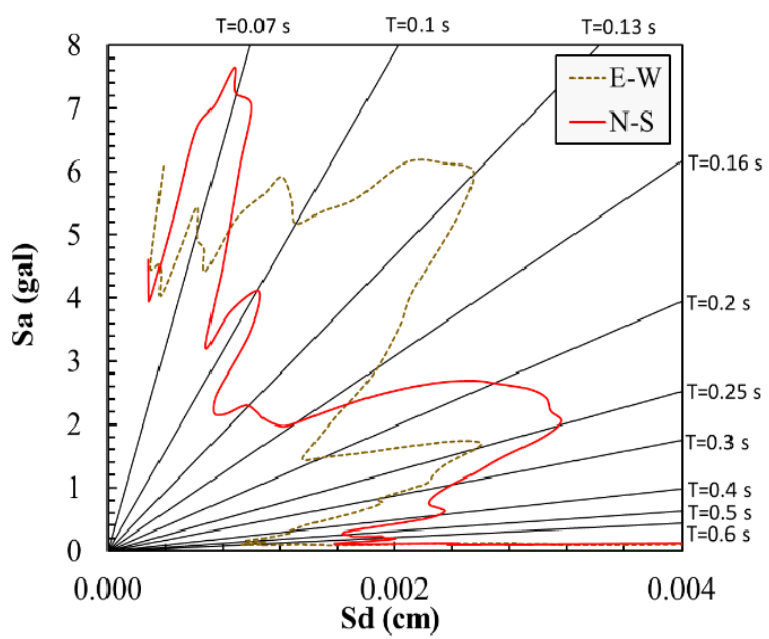

Fig. 14. Response spectra. HERM building - June 3, 2014.
Table 4. Acceleration at the basement (gals).

\begin{tabular}{ccccccc}
\hline \multirow{2}{*}{ Date } & \multicolumn{2}{c}{ HERM } & \multicolumn{2}{c}{ PC-UNI } & \multicolumn{2}{c}{ FIC-UNI } \\
\cline { 2 - 7 } & NS & EW & \multicolumn{1}{c}{ NS } & \multicolumn{1}{c}{ EW } & \multicolumn{1}{c}{ NS } & \multicolumn{1}{c}{ EW } \\
\hline $2012 / 11 / 03$ & - & - & -3.45 & -3.05 & - & - \\
$2012 / 12 / 28$ & - & - & -4.84 & -2.95 & 2.57 & 3.45 \\
$2013 / 10 / 18$ & - & - & -5.59 & 6.38 & -5.92 & 6.39 \\
$2013 / 11 / 25$ & - & - & -15.11 & 15.89 & -13.02 & 18.66 \\
$2014 / 02 / 20$ & 1.28 & -1.70 & 1.01 & -1.11 & 1.57 & -1.30 \\
$2014 / 02 / 22$ & - & - & -7.34 & 6.65 & 8.44 & 11.58 \\
$2014 / 04 / 26$ & -1.73 & -2.05 & 5.65 & 6.85 & 4.99 & 6.65 \\
$2014 / 06 / 03$ & 14.90 & 12.19 & 18.83 & -25.89 & 26.13 & 24.01 \\
\hline
\end{tabular}

\subsection{PC-UNI}

From the recorded data, the maximum acceleration is $18.83 \mathrm{gal}$ and $25.89 \mathrm{gal}$ in NS and EW directions, respectively. This record is shown in the Fig. 15.

The maximum amplification from the acceleration at the basement to that at the roof is 1.5 and 1.1 for NS and EW directions, respectively, for PC-UNI building (one basement and three stories).

The average predominant period of PC-UNI building using the recorded data of events shown in Table 2 is 0.31 seconds for NS direction and 0.25 seconds for EW direction. In the same way as the HERM building, this value does not present significant variation, because quakes are slight; while, the damping ratio varies from $2-4 \%$.

The Fourier spectra of signals of the PC-UNI building for the strongest event in NS and EW directions are presented in Fig. 16.

The response spectra using signals from the basement of the PC-UNI building for the strongest event since the installation of the building monitoring network are shown in Fig. 17. According to this signal (at ground), structures with fundamental periods from $0.15-0.25$ seconds presented higher response; note that the fundamental period of the PC-UNI building is in this range.

\subsection{FIC-UNI}

From the recorded data, the maximum acceleration is $26.13 \mathrm{gal}$ and $24.01 \mathrm{gal}$ in NS and EW directions, respectively. This record is shown in the Fig. 18.

The maximum amplification from the acceleration at the basement to that at the roof is 2.3 and 1.9 for NS and EW directions, respectively, for the FIC-UNI building (one basement and three stories).

The Fourier spectra of signals of the FIC-UNI building for the strongest event in NS and EW directions are presented in Fig. 19. The average predominant period using the recorded data of events shown in Table 3 is 0.17 seconds for NS direction and 0.18 seconds for EW direction of the FIC-UNI building. The damping ratio is within 23\% using the events listed in Table 3.

The response spectra using signals from the basement of the FIC-UNI building for the strongest event since the installation of the building monitoring network are shown 


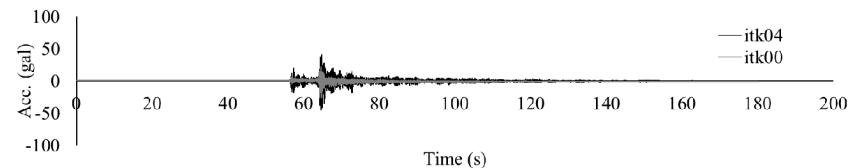

a) $\mathrm{NS}$

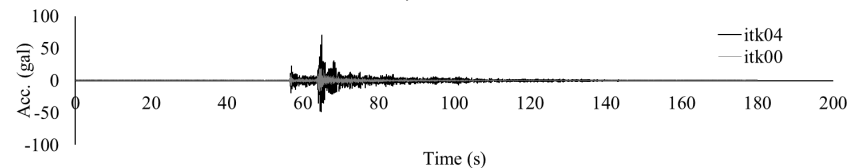

b) $\mathrm{EW}$

Fig. 15. 3D model of PC-UNI building.

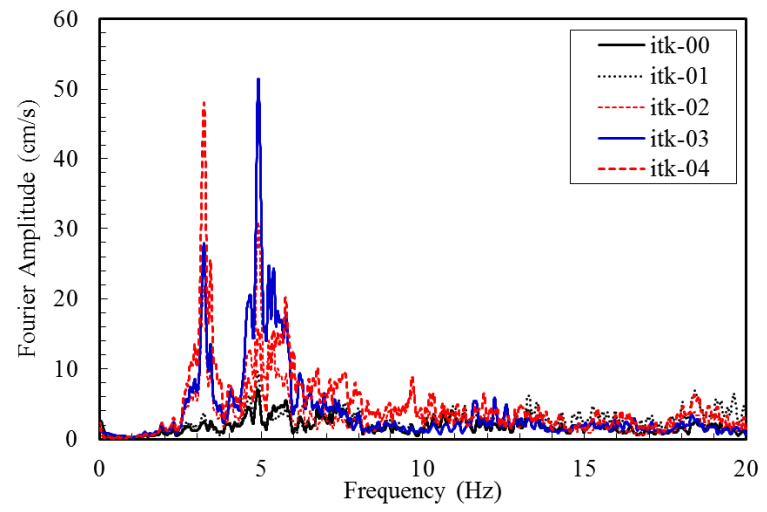

a) NS

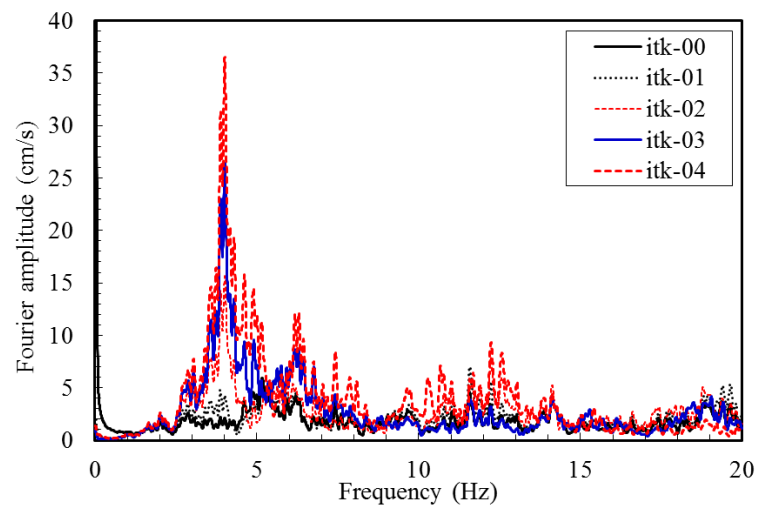

b) EW

Fig. 16. Fourier spectra. PC-UNI building - June 3, 2014.

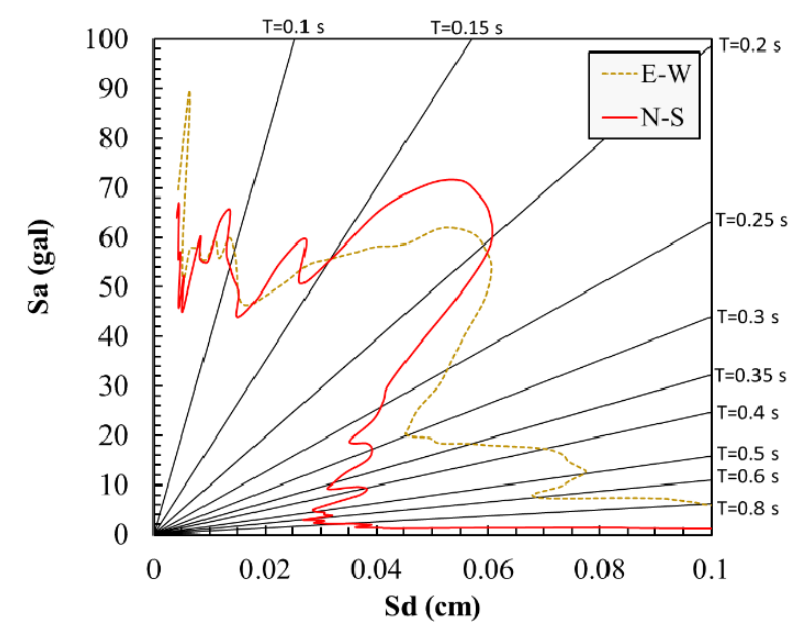

Fig. 17. Response spectrum. PC-UNI building - June 3, 2014.

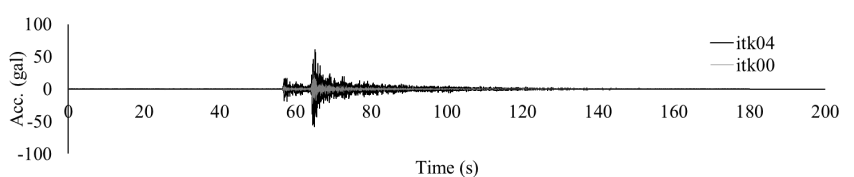

a) NS

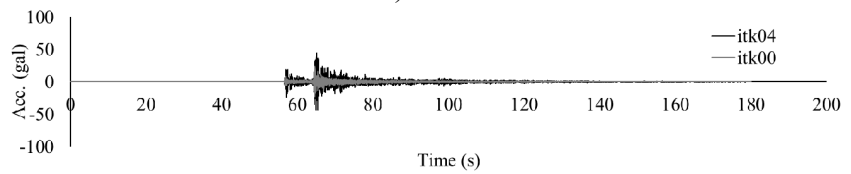

b) $\mathrm{EW}$

Fig. 18. 3D model of FIC-UNI building.

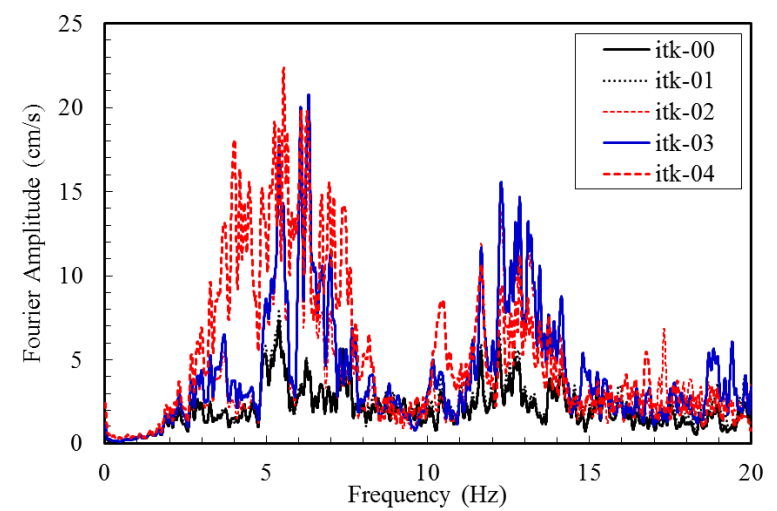

a) NS

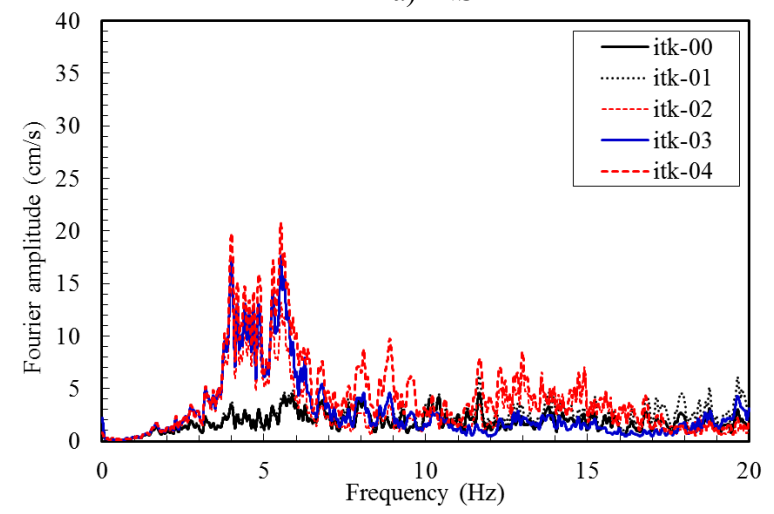

b) $\mathrm{EW}$

Fig. 19. Fourier spectrum. FIC-UNI building - June 3, 2014.

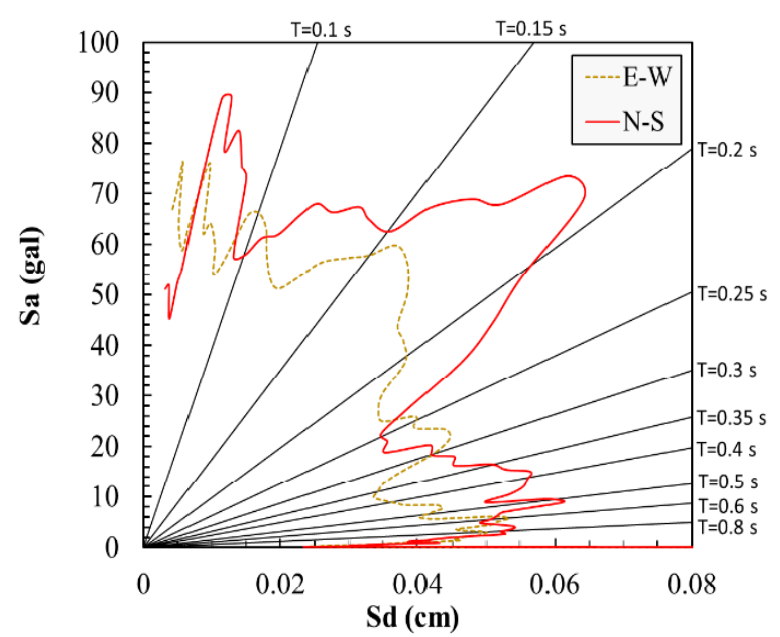

Fig. 20. Response spectrum. FIC-UNI building - June 3, 2014. 
Table 5. Predominant periods (seconds).

\begin{tabular}{lllcc}
\hline \multirow{2}{*}{ Building } & \multicolumn{2}{c}{ Former studies } & \multicolumn{2}{c}{ In this study } \\
\cline { 2 - 5 } & Long. & Trans. & $\begin{array}{c}\text { Long. } \\
\text { (EW) }\end{array}$ & $\begin{array}{c}\text { Trans. } \\
\text { (NS) }\end{array}$ \\
\hline HERM & $1.74^{*}$ & $1.93^{*}$ & 0.98 & 0.98 \\
PC-UNI & $0.23^{* *}$ & $0.28^{* *}$ & 0.25 & 0.31 \\
FIC-UNI & $0.195^{* *}$ & $0.162^{* *}$ & 0.18 & 0.17 \\
\hline
\end{tabular}

${ }^{*}$ Theoretical analysis, ${ }^{* *}$ Monitoring network

in Fig. 20. Using signals from itk-00 (at ground), similarly to the PC-UNI building, structures with fundamental periods within $0.15-0.25$ seconds presented higher response; note that the fundamental period of the FIC-UNI building is in this range.

Table 5 summarized predominant periods in longitudinal and transversal directions obtained in former studies and the present study, i.e. by the monitoring network. Former studies of HERM building present theoretical results only.

\section{Conclusions}

The Building monitoring network has been installed in three buildings in Lima City as an output of the Project for Enhancement of Earthquake and Tsunami Disaster Mitigation Technology in Peru supported by JST and JICA. This network is the first of its kind in Peru.

Microtremor measurements and acceleration records present similar results, since buildings are not damaged, and both measurements, from microtremor and monitoring network, recorded low amplitudes vibrations.

The Building monitoring network is working since 2011; nevertheless, recorded quakes have low amplitudes, and the response of the target buildings is in the elastic range (maximum response acceleration is less than $0.1 \mathrm{G}$ ). Dynamics characteristics of the target buildings do not present significant variation, because these buildings were subjected to low amplitude vibrations.

Since the building monitoring network has been recently implemented, the recorded data is very limited for the investigation of the target buildings (typical structures). However, Expectations are high in order to understand the dynamic behavior of typical Peruvian buildings, and to be able to anticipate the buildings response and to reduce their risk, e.g. retrofitting techniques which are being preparing by other researches involve in Japan-Peru SATREPS project.

\footnotetext{
Acknowledgements

Authors would like to express their gratitude the Japan Science and Technology Agency (JST) and the Japan International cooperation Agency (JICA) for the support to the Japan-Peru SATREPS Project during this research. A special thanks to Dr. Fumio Yamazaki, Principal Investigator of the SATREPS project. Also, their gratitude to Mr. Salinas, Mr. Gonzales and Mr. Vargas, students of the National University of Engineering for their support during the signal processing.
}

\section{References:}

[1] A. Camacho, "Structural Vulnerability of main buildings of the Faculty of Civil Engineering - UNI," Undergraduate Thesis for Civil Engineering, FIC-UNI, Lima, Peru, 2010.

[2] A. K. Chopra, "Dynamic of Structures: Theory and Applications to Earthquake Engineering," $3^{\text {rd }}$ edn, Prentice Hall, New Jersey, 2007.

[3] M. Diaz, K. Kusunoki, and A. Tasai, "Analytical Study on the Seismic Performance Estimation using the Equivalent Damping and Response Reduction Ratio for Aftershocks," Journal of Structural Engineering of Architectural Institute of Japan, Vol.59B, pp. 399-408, 2013.

[4] C. Fajardo, "Structural Evaluation of One of Buildings of Edgardo Rebagliati Martins Hospital," Undergraduate Thesis for Civil Engineering, FIC-UNI, Lima, Peru, 2012.

[5] P. Gibu, C. Zavala, R. Proaño et.al, "Building Monitoring Earthquake Response Network In Lima," Proc. of the $10^{\text {th }}$ Int. Conf. on Urban Earthquake Engineering, Tokyo Institute of Technology, 2013.

[6] W. Iwan, "Health and Performance Evaluation using real-time hysteretic behavior," Proc. of $1^{\text {st }}$ Int. Conf. on Structural Health Monitoring and Intelligent Infrastructure, pp. 1031-1038, 2003.

[7] K. Kusunoki, T. Akira, and M. Teshigawara, "Development of Building Monitoring System to Evaluate Residual Seismic Capacity after an Earthquake," Proc. of $15^{\text {th }}$ World Conf. on Earthquake Engineering, Paper No.939, 2012.

[8] K. Morita and M. Teshigawara, "Damage Detection and Estimation of Buildings through Measurements," Proc. of $1^{\text {st }}$ Int. Conf. on Structural Health Monitoring and Intelligent Infrastructure, pp. 447$454,2003$.

[9] L. Moya and C. Zavala, "Structural Evaluation of Block G2 of the Faculty of Civil Engineering - UNI," Preliminary Report for Satreps- JST-JICA Project, 2012.

[10] A. Shibata, "Dynamic Analysis of Earthquake Resistant Structures," $1^{\text {st }}$ edn in English, Tohoku University Press, 2010.

[11] C. Zavala and R. Reyna, "Microtermor measurement on Main Building of the National University of Engineering," Preliminary Report for Satreps- JST-JICA Project, 2011.

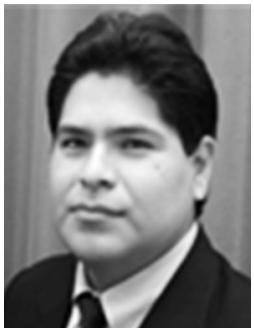

\section{Name:}

Miguel Diaz Figueroa

Affiliation:

Associate Professor, National University of Engineering

Address:

Av. Tupac Amaru 1150, Lima 25, Peru

Brief Career:

2006 Bachelor of Engineering, Faculty of Civil Engineering, National

University of Engineering, Peru

2006 Joined to Japan Peru Center for Earthquake Engineering and Disaster Mitigation

2008 Master of Disaster Management - Earthquake Engineering, Building Research Institute, Japan

2013 Doctor of Engineering, Graduate School of Engineering, Yokohama National University, Japan

2014 Associate Professor, National University of Engineering, Peru

Selected Publications:

- "Evaluation of seismic response under major earthquakes of the Carlos

Lanfranco Hospital," Lima, 2013.

- "Analytical Study on the Seismic Performance Estimation using the Equivalent Damping and Response Reduction Ratio for Aftershocks," Journal of Structural Engineering, Architectural Institute of Japan, Vol.59B, pp. 399-408, 2013.

- "Experimental Study on Residual Seismic Performance of Scaled Three-Story Steel Frames Tested on a Shaking Table," Proc. of Int. Symposium on Earthquake Engineering of Japan Association for Earthquake Engineering, 2012.

Academic Societies \& Scientific Organizations:

- Peruvian Engineering Association (CIP)

- Architectural Institute of Japan (AIJ) 